\title{
$\bullet$ \\ IJCRR \\ A Survey on Chennai Population on Awareness and Practice on Importance of Oral Hygiene in Present Covid-19 Situation
}

Section: Healthcare

Sci. Journal Impact

Factor: 6.1 (2018)

ICV: 90.90 (2018)

\author{
Bipin Maheshwaran', Sindhu Ramesh ${ }^{2}$, Kavitha S ${ }^{3}$
}

\begin{abstract}
'Saveetha Dental College and Hospitals, Saveetha Institute of Medical and Technical Sciences, Saveetha University, Chennai, India; 'Professor, Department of Conservative Dentistry and Endodontics, Saveetha Dental College and Hospitals, Saveetha Institute of Medical and Technical Sciences, Saveetha University, Chennai, India; 3 Senior Lecturer, Department of Saveetha Dental College and Hospitals, Saveetha Institute of Medical and Technical Sciences, Saveetha University, Chennai, India.
\end{abstract}

\section{ABSTRACT}

Introduction: Oral hygiene is the practice of keeping one's oral cavity neat, clean in order to avoid any disease initiation, progression. Oral health approaches should be customized to the lifestyles of children, and adults in order to enable them to improve personal oral hygiene and oral health.

Aim: The purpose of the study was to know about the awareness and practice of oral hygiene among the general population and maintenance of oral health among the adult population in the present COVID situation. It has been difficult in obtaining dental treatment in the current COVID situation as the pandemic peaks high every day. At home, hygiene awareness is important.

Methodology: A total of nearly 200 participants were requested to participate in the study. The questionnaire had 20 items which were designed in such a way to evaluate the awareness and attitude of oral hygiene in the current COVID situation. A small population of Chennai of 174 was aware of oral hygiene, especially during the current COVID-19 situations.

Results: Results showed that [50.8\%] of this particular age group felt that oral hygiene was as important as general measures, [81\%] of the study population felt dental treatment is more important when compared to other medical treatments. Pearson Chisquare test value $9.372 ;$ p-value $=0.154(>0.05)$ which is statistically not significant. Nowadays even though we have advanced in awareness of oral health care, it's not yet reached the entire population.

Conclusion: Most of the people these days are aware of the basic oral hygiene techniques and show a responsible attitude towards these procedures. But there exists a circle of the population who are not aware of various oral hygiene methods. This may lead to poor oral health care.

Key Words: Oral health, Dental treatment, Oral hygiene, Dental awareness, COVID-19, Brushing techniques.

\section{INTRODUCTION}

Oral hygiene is the basic practice of keeping the mouth clean and healthy by brushing and flossing to prevent oral diseases. The main purpose of oral hygiene is to prevent the formation of plaque, the sticky film of bacteria that forms on the teeth. Dental problems are one of the biggest problems in both developing and developed countries today. As we know, brushing and flossing remove plaque from teeth and antiseptic mouthwashes kill some of the bacteria that form plaque. Oral health knowledge is considered to be an essential measure for health-related behaviour ${ }^{1-8}$. One of the most important factors that decide the dental health of a population is the outlook of its people toward their dentition ${ }^{3,9-12}$. Even parents should be advised to follow up to maintain proper oral health among infants and children ${ }^{13-20}$. As the study maintains $70 \%$ of the children have poor brushing habits in which may lead to tooth decay and gum diseases ${ }^{21-24}$.

As oral health is a vital component and an intrinsic part of general health, certain interventions are needed to educate people regarding the maintenance of their oral health ${ }^{25,26}$. Community oral hygiene promotion must attempt to maximize opportunities for oral health for all and reduce inequalities by removing financial barriers. Oral health strategies should be adapted to childrens' and adults' lifestyles and

\section{Corresponding Author:}

Sindhu Ramesh, Professor, Department of Conservative Dentistry and Endodontics, Saveetha Dental College and Hospitals, Saveetha Institute of Medical and Technical Sciences, Saveetha University, 162, PH Road, Chennai 600077, Tamil Nadu, India; Contact: 9840136543; Email: sindhuramesh@saveetha.com

ISSN: 2231-2196 (Print) ISSN: 0975-5241 (Online)

Received: $24.07 .2020 \quad$ Revised: 26.08 .2020

Accepted: 20.09 .2020

Published: 20.10 .2020 
abilities so as to allow them to make age decisions to improve personal oral hygiene and oral health ${ }^{27-30}$. Oral care comprises a wide range of spectrum of activities ranging from care, prevention, and diagnosis. Oral care practices have been proved to be an effective preventive measure for an individual to maintain good oral health ${ }^{5,31,1}$. People living in developing countries especially people with lower economic status have lacunae in oral health awareness ${ }^{32-34}$. Several studies suggest that countless numbers of dental health information programs have been conducted in schools and other settings. However, it suggests that these efforts will not succeed in influencing the behavior until the people are not aware of the importance of oral health ${ }^{35,36}$. And halitosis is an oral health disease characterized by a strong odorous smell, caused by inadequate oral hygiene, insufficient dental brushing, decreased salivary flow rate, tobacco use, and other systemic disorders. This is one of the major problems in today's majority of the population ${ }^{37-42}$. Early detection of these diseases and diagnosing proper treatment will reduce the risk of these dental issues. Even children these days have different perceptions and assumptions about dental oral hygiene through which they developed an attitude towards Maintenance of oral hygiene and its benefits ${ }^{43-46}$ Several studies have done by our team both clinical trial ${ }^{47-51}$ and Surveys ${ }^{52,53}$, Reviews based on endodontic procedures ${ }^{47,50,54-60}$ over the past 5 years. Now we are focusing on epidemiological surveys. The idea had stemmed from the current interest in the community. The Aim of this present survey was on the Chennai population on awareness and practice on the importance of oral hygiene in the present COVID-19 situation.

\section{MATERIALS AND METHODS}

\section{Study Design}

A cross-sectional study was conducted among 174 dental students from April - May 2020.

\section{Ethical Approval}

Ethical permission and approval (SRB/SDC/BDS/001) for the project was obtained from the institutional review board of Saveetha Institute of Medical And Technical Sciences, Chennai, India on date 25/04/2020 .

\section{Eligibility Criteria}

Adult Population of Chennai who was willing to participate.

\section{Data Collection}

The questionnaire was shared online via Google forms and responses were obtained from 174 participants. The data for 20 questions were compiled and represented in pie charts obtained from the google forms. (https://docs.google. com/forms/d/e/1FAIpQLSd8QD_LHuH4g52I-1 o5w7daU0nYKCmlFgrCFxfx-kMTUhJ8vA/viewform?usp=sf_link)

\section{Sample Size}

This study was done on the population of Chennai. The subjects were taken from the rural, urban areas of Chennai. A total of nearly 174 participants were requested to participate in the study. Out of which 21 participants did not take up the survey and 5 were incomplete forms that were excluded from the study. Hence, the total number of participants was 174.

\section{Study Subjects}

The subjects' age limits were given importance to participate in the survey. The questionnaire had 20 items in it which was designed in such a way to evaluate the awareness and attitude of oral hygiene in the present COVID 19 situation. Assessment of subjects' awareness and attitude towards oral hygiene included the questions relating the knowledge of basic techniques of oral hygiene, attitude about dental case and body case, about awareness of modern dental treatments, attitude towards a regular visit to the dentist. The subjects were requested to respond to each item in the specific format given at the end of each item. All the participants were allowed to choose one of the given three to four choices for each item in the questionnaire.

\section{Study Methods}

Self-administered questionnaire of 12 close-ended questions were prepared and it was distributed among the Chennai population through online survey forms "GOOGLE FORMS". Demographic details were also included in the questionnaire.

\section{Data Quality Assurance}

The collected data were checked regularly for clarity, competence, consistency, accuracy, and validity. The necessary correction was made on questionnaires that need correction accordingly and invalid questionnaires were removed before the actual data collection.

\section{Statistical Analysis}

Data were analyzed with SPSS version (22.0). Descriptive statistics as number and percent were calculated to summaries qualitative data. Chi-square test was used to analyze and compare the education level of students and their knowledge of oral hygiene in the present COVID situation. The confidence level was $95 \%$ and of statistical significance $\mathrm{P}<0.05$. Finally, the result was presented by using bar charts and frequency tables.

\section{RESULTS AND DISCUSSION}

In this survey, among the questions that are asked, the majority of them told age, gender, year of study, and awareness about oral hygiene. The results of the survey are presented in the following charts. 
Table 1: The distribution of cases that were included for the study based on Gender and age. The maximum number of respondents was between the age group 20-25 years.

\begin{tabular}{llcc}
$\begin{array}{l}\text { Demographic } \\
\text { variables }\end{array}$ & Categories & $\begin{array}{c}\text { No. of re- } \\
\text { spondents }\end{array}$ & $\begin{array}{c}\text { Percentage } \\
\%\end{array}$ \\
\hline Gender & Female & 41 & $22.8 \%$ \\
\multirow{2}{*}{ Age (years) } & Male & 142 & $77.2 \%$ \\
& Below 20 years & 38 & $\mathbf{2 2 . 2} \%$ \\
& 20-25 years & 118 & $69.0 \%$ \\
& 25-30 years & 1 & $0.6 \%$ \\
& Above 30 years & 14 & $8.2 \%$ \\
\hline
\end{tabular}

Out of 174 cases, $\mathbf{2 2 . 8} \%$ were female and $77.2 \%$ were male.

Table 2: The distribution of responses of participants on what kind of oral hygiene measure can be followed, showing statistically no significant difference between the variables. $(p>0.05)$

\begin{tabular}{lcccc} 
& $\begin{array}{c}\text { In your opinion, Do you feel } \\
\text { oral hygiene practices are as } \\
\text { Age Parameter }\end{array}$ & $\begin{array}{c}\text { important as general meas- } \\
\text { ures in day to day life? } \\
\text { Yes }\end{array}$ & No value & Not sure \\
Below 20 years & 28 & 8 & 2 & \\
20-25 years & 87 & 26 & 5 & 0.154 \\
25-30 years & 1 & 0 & 0 & \\
Above 30 years & 6 & 8 & 0 & \\
Total & 122 & 42 & 7 & \\
\hline
\end{tabular}

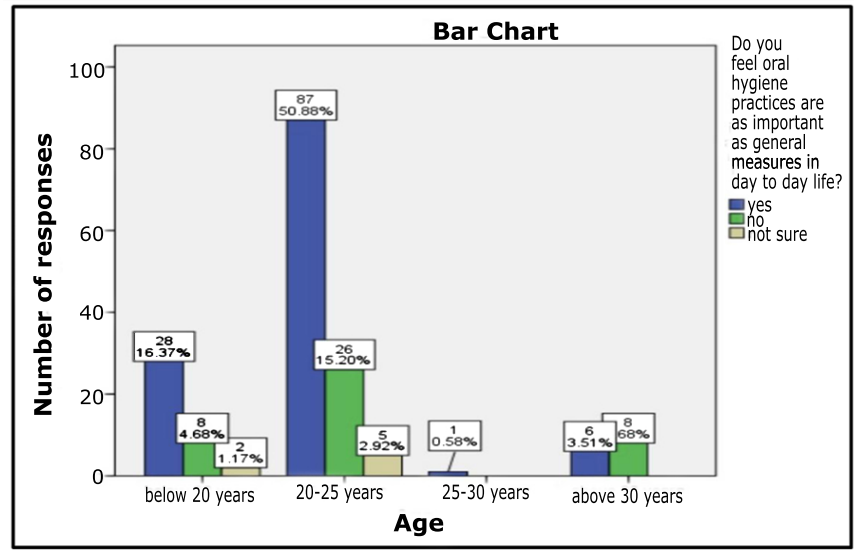

Figure 1: Bar chart showing the association between different age groups of participants and responses for, do you feel oral hygiene practices are as important as general measures. The $X$-axis represents the different age groups of participants and Y-axis represents the number of responses obtained; The majority of respondents belonging to the age group 20-25 years responded 'Yes'(50.88\%). The association was analyzed using Chi-square test (9.372) and was found to be statistically no significant difference $(p>0.05)$

Table 3: The distribution of responses of participants on what kind of oral hygiene measures to be followed on a daily basis, showing statistically no significant difference between the variables. $(p>0.05)$

\begin{tabular}{|c|c|c|c|c|c|c|c|c|}
\hline \multirow[b]{2}{*}{ Age parameter } & \multicolumn{7}{|c|}{ In your opinion, What kind of oral hygiene measures do you follow on a daily basis? } & \multirow[b]{2}{*}{ Pvalue } \\
\hline & $\begin{array}{c}\text { Tooth } \\
\text { brushing }\end{array}$ & $\begin{array}{l}\text { Mouth } \\
\text { washes }\end{array}$ & flossing & $\begin{array}{c}\text { All of the } \\
\text { above }\end{array}$ & $A$ and $B$ & $A$ and $C$ & All 7 options & \\
\hline Below 20 years & 4 & 6 & 4 & 9 & 10 & 4 & 1 & \\
\hline 20- 25 years & 14 & 16 & 14 & 27 & 43 & 4 & o & \\
\hline $25-30$ years & o & o & o & o & 1 & o & o & 0.634 \\
\hline Above 30 years & 1 & 4 & 2 & 5 & 1 & 1 & 1 & \\
\hline Total & 19 & 26 & 20 & 41 & 55 & 9 & 2 & \\
\hline
\end{tabular}




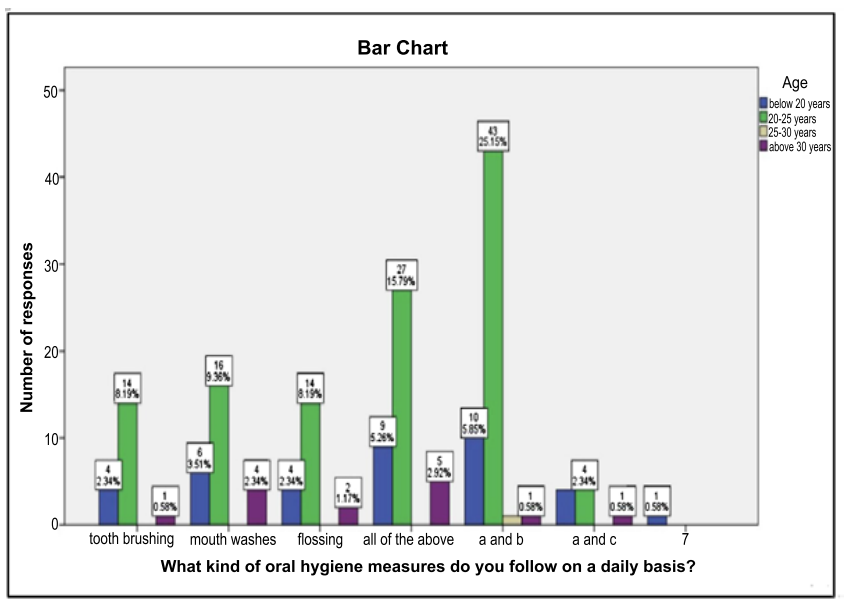

Figure 2: Bar chart showing the association between different age groups of the study population and the responses for Oral hygiene measures followed on a daily basis. The $X$-axis represents the number of responses and $Y$-axis represents the different age groups. The majority of respondents belonging to the age group 20-25 years responded they would follow both brushing and flossing (25.15\%). The association was analyzed using Chi-square test (15.411) and was found to be statistically no significant difference $(p>0.05)$

Table 4: Shows the distribution of responses of participants on, In your opinion, Do you visit the dentist on a frequent basis? When was your last visit? , showing statistically no significant difference between the variables $(p>0.05)$.

\begin{tabular}{|c|c|c|c|c|c|}
\hline \multirow[t]{2}{*}{$\begin{array}{l}\text { Age Pa- } \\
\text { rameter }\end{array}$} & \multicolumn{4}{|c|}{$\begin{array}{l}\text { In your opinion, Do you visit the } \\
\text { dentist on a frequent basis? When was } \\
\text { your last visit? }\end{array}$} & \multirow[t]{2}{*}{$\begin{array}{l}\mathbf{P} \\
\text { value }\end{array}$} \\
\hline & $\begin{array}{l}\text { I visit } \\
\text { every } 6 \\
\text { months }\end{array}$ & $\begin{array}{l}\text { I have } \\
\text { never } \\
\text { been to a } \\
\text { dentist }\end{array}$ & $\begin{array}{l}\text { I visit } \\
\text { only } \\
\text { when I } \\
\text { visit a } \\
\text { dentist }\end{array}$ & $\begin{array}{l}\text { I Am not } \\
\text { inter- } \\
\text { ested } \\
\text { to visit } \\
\text { dentist }\end{array}$ & \\
\hline $\begin{array}{l}\text { Below } 20 \\
\text { years }\end{array}$ & 6 & 8 & 19 & 5 & 0.120 \\
\hline $\begin{array}{l}20-25 \\
\text { years }\end{array}$ & 25 & 25 & 61 & 7 & \\
\hline $25-30$ years & o & o & 1 & o & \\
\hline $\begin{array}{l}\text { Above } 30 \\
\text { years }\end{array}$ & 8 & 2 & 4 & o & \\
\hline Total & 39 & 35 & 85 & 12 & \\
\hline
\end{tabular}

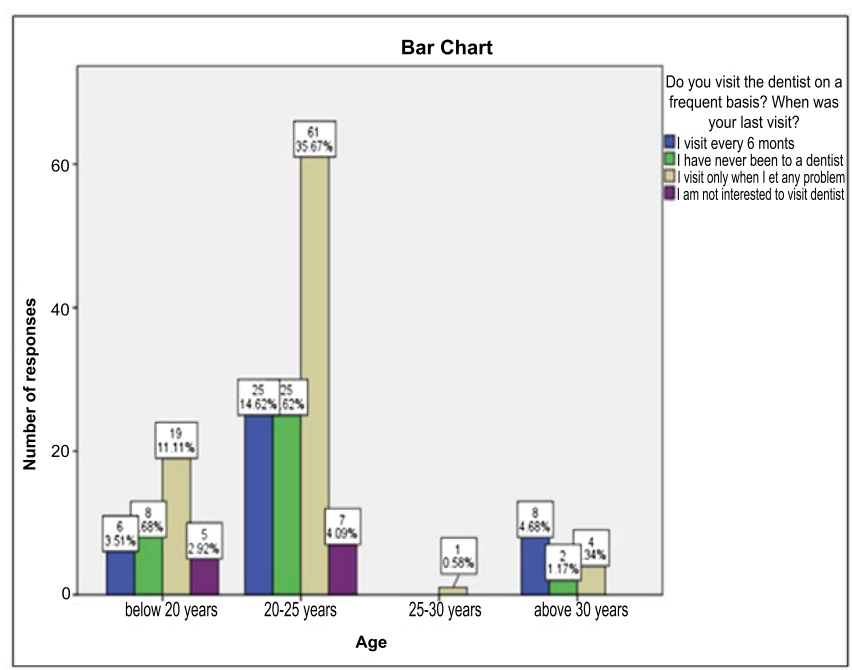

Figure 3: Bar chart showing the association between the different age groups of participants and responses for estimation of regular clinical visits. The $\mathrm{X}$-axis represents the different age groups of study population and $Y$-axis represents the number of responses obtained. The majority of respondents belonging to the age category 20-25 years responded that they visit a dentist only if they face any problem (35.67\%). The association was analyzed using Chi-square test (14.077) and was found to be statistically no significant difference $(p>0.05)$.

Table 5: The distribution of responses of participants on, In your opinion, Are you aware of the fact that poor dental health is linked to many serious diseases and conditions? showing statistically no significant difference between the variables (p>0.05).

\begin{tabular}{lcc} 
In your opinion, Are you & $\begin{array}{c}\text { Inte of the fact that poor } \\
\text { aware } \\
\text { dental health is linked to } \\
\text { many serious diseases and } \\
\text { conditions? }\end{array}$ & P value \\
Age Parameter & Yes & 14 \\
Below 20 years & 24 & 49 \\
20-25 years & 69 & 0 \\
25-30 years & 1 & 7 \\
Above 30 years & 7 & 70 \\
Total & 101 & 0.694 \\
\hline
\end{tabular}




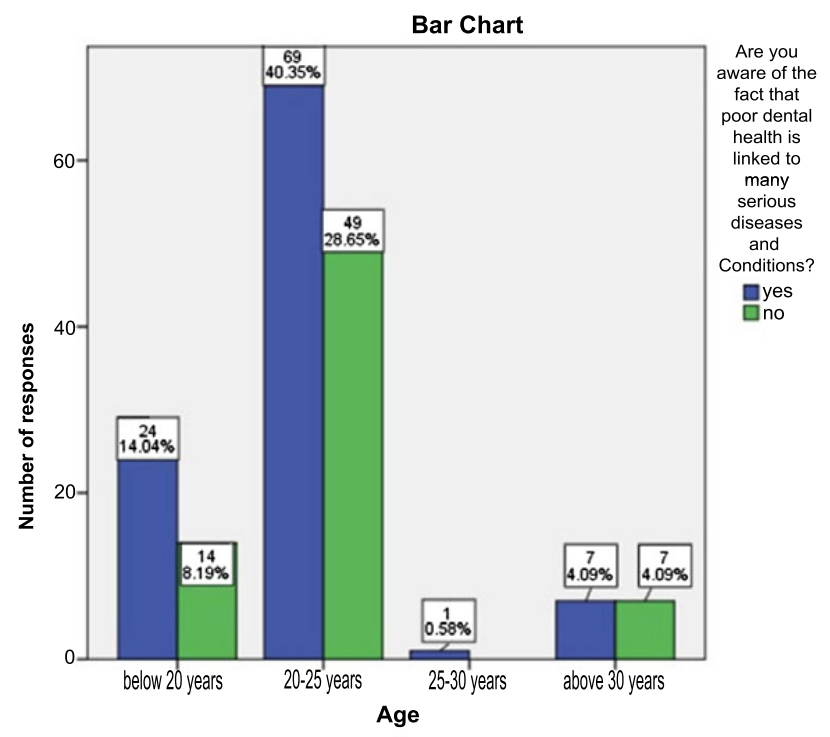

Figure 4: Bar chart showing the association between different age groups of participants and the responses for awareness of poor health and associated diseases. The $X$-axis represents different age groups of participants and the $Y$-axis represents the number of responses obtained. The majority of respondents belonging to the age group 20-25 years responded 'Yes' (40.35\%). The association was analyzed using Chi-square test (1.449) and was found to be statistically no significant difference $(p>0.05)$.

Table 6: The distribution of responses of participants on, in your opinion, Do you think in the present COVID-19 situation maintaining oral hygiene is as important as oral hygiene? showing statistically no significant differences between the variables ( $p>0.05)$.

\begin{tabular}{|c|c|c|c|c|}
\hline \multirow[t]{2}{*}{ Age Parameter } & \multicolumn{3}{|c|}{$\begin{array}{l}\text { In your opinion, Do you } \\
\text { think in the present } \\
\text { COVID-19 situation } \\
\text { maintaining oral hygiene } \\
\text { is as important as oral } \\
\text { hygiene? }\end{array}$} & \multirow[t]{2}{*}{ P value } \\
\hline & Yes & No & May be & \\
\hline Below 20 years & 21 & 10 & 7 & \multirow{5}{*}{0.748} \\
\hline 20-25 years & 61 & 25 & 32 & \\
\hline $25-30$ years & 1 & o & o & \\
\hline Above 30 years & 6 & 5 & 3 & \\
\hline Total & 89 & 40 & 42 & \\
\hline
\end{tabular}

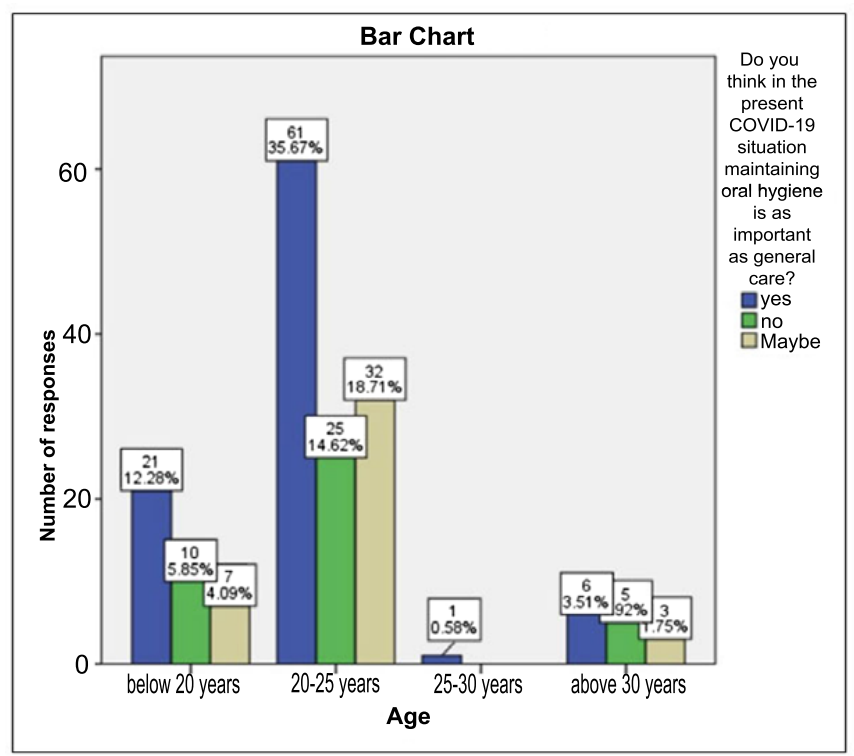

Figure 5: Bar chart showing the association between different age groups and maintenance of General hygiene and Oral health care in COVID-19 situation. $X$ axis represents the different age groups of participants and $Y$ axis represents the number of responses obtained. Majority of respondents belonging to the age group 20-25 years responded 'Yes' (35.67\%). The association was analyzed using chi-square test (3.473) and was found to be statistically no significant difference $(p>0.05)$.

Table 7: The distribution of responses of participants on, In your opinion, Did you contact any dental surgeon or dental health care professional for appropriate information on maintaining oral hygiene especially in this situation? showing statistically no significant differences between the variables (p>0.05).

\begin{tabular}{lcccc} 
Age Parameter & $\begin{array}{c}\text { In your opinion, Did you } \\
\text { contact any dental surgeon } \\
\text { or dental health care pro- } \\
\text { fessional for appropriate } \\
\text { information on maintaining } \\
\text { oral hygiene especially in } \\
\text { this situation? }\end{array}$ & $\begin{array}{c}\text { P } \\
\text { value }\end{array}$ \\
& Yes & No & $\begin{array}{c}\text { I don't feel we } \\
\text { need that }\end{array}$ & \\
Below 20 years & 12 & 19 & 7 & 0.421 \\
20-25 years & 23 & 78 & 17 & \\
25-30 years & 0 & 1 & 0 & \\
Above 30 years & 5 & 6 & 3 & \\
Total & 40 & 104 & 27 & \\
\hline
\end{tabular}




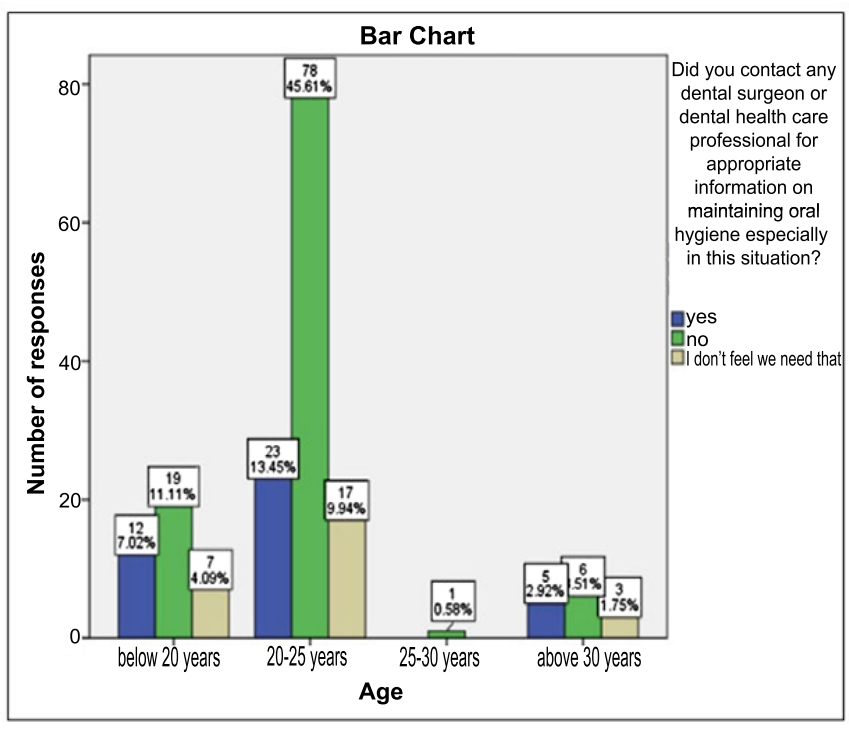

Figure 6: Bar chart showing the association between different age groups of participants and responses for the importance of having concern on Maintenance of Oral health and hygiene with dentists. X-axis represents the different age groups of participants and $\mathrm{Y}$-axis represents the number of responses obtained. Majority of respondents belonging to the age group 20-25 years responded 'No' (45.61\%) The association was analyzed using chi-square test value (6.016) and was found to be statistically no significant difference $(p>0.05)$.

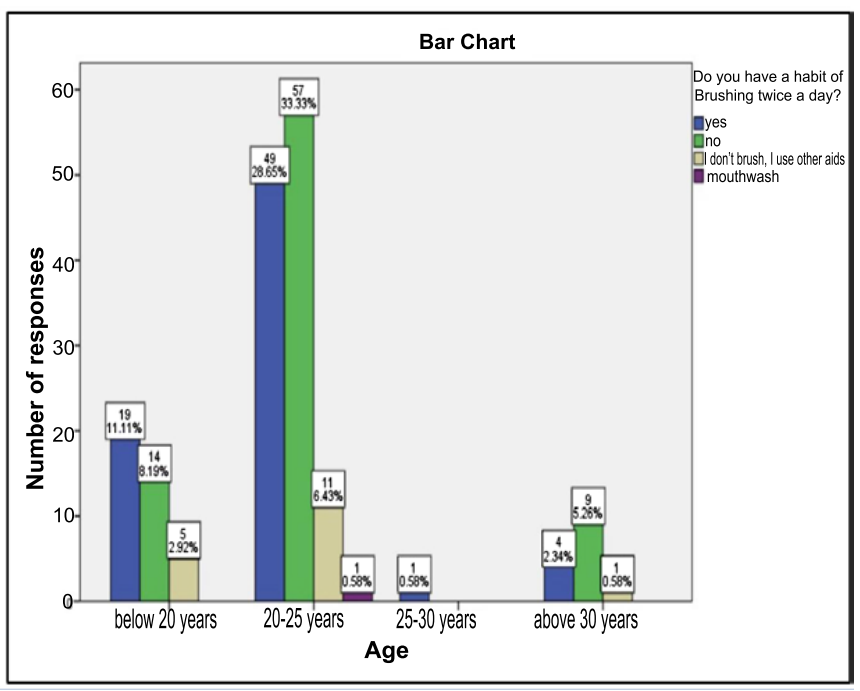

Figure 7: Bar chart showing the association between the different age groups of participants and the responses for frequency of brushing a day. X-axis represents the different age groups of participants and Y-axis represents the number of responses obtained .Majority of respondents belonging to the age group 20-25 years responded 'No' (33.33\%) The association was analyzed using chi-square test (5.282) and was found to be statistically no significant difference $(p>0.05)$.

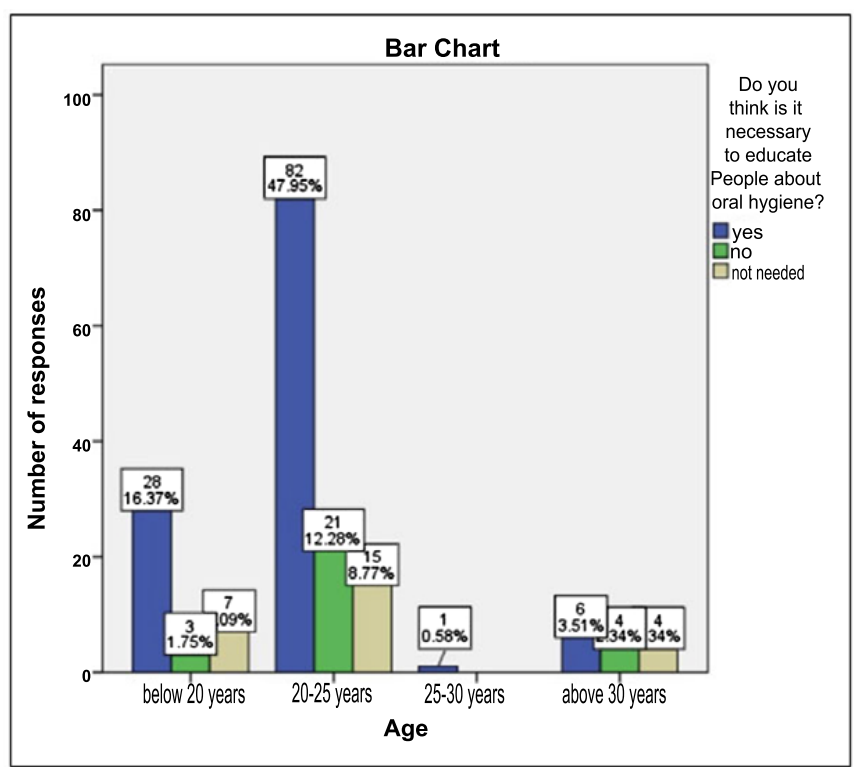

Figure 8: Bar chart showing the association between the different age groups of participants and the responses for necessity of education about oral hygiene. X-axis represents the different age groups of study population and Y-axis represents the number of responses obtained. Majority of respondents belonging to the age group 20-25 years responded 'Yes' $(47.95 \%)$. The association was analyzed using chi square test (7.445) and was found to be statistically no significant difference $(p>0.05)$.

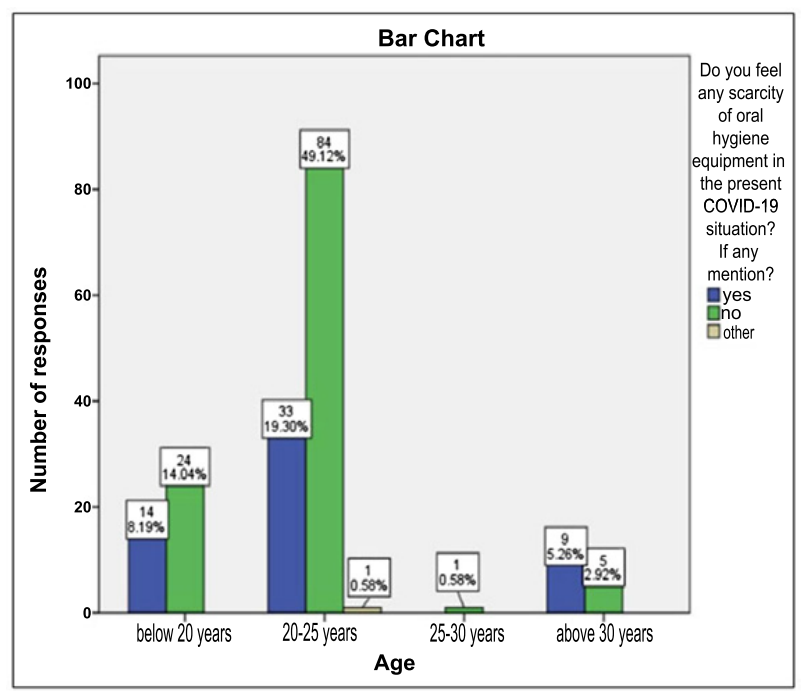

Figure 9: Bar chart showing the association between different age groups of participants and the responses for scarcity of oral hygiene equipment in the present COVID-19 situation. $X$-axis represents the different age groups of participants and the $\mathrm{Y}$-axis represents the number of responses. Majority of respondents belonging to the age group 20-25 years responded 'No' (49.12\%). The association was analyzed using chi-square test (8.657) and was found to be statistically no significant difference $(p>0.05)$ 


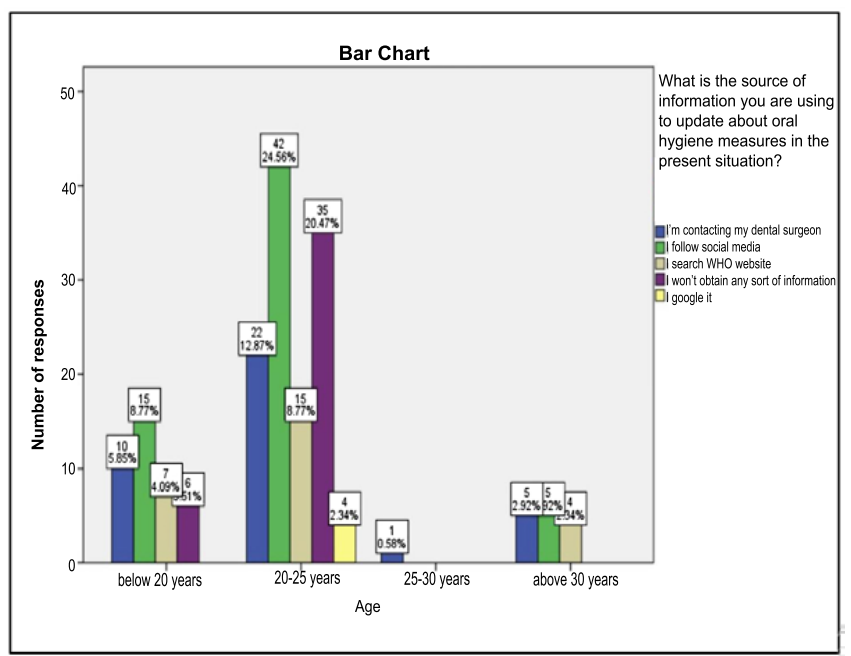

Figure 10: Bar chart showing the association between different age groups of participants and the responses for an update on a source of information about Oral hygiene measures in COVID-19 situation. X-axis represents the different age groups of participants and Y-axis represents the number of responses obtained. Majority of respondents belonging to the age group 20-25 years responded that they follow social media $(24.56 \%)$ The association was analyzed using chi-square test (15.906) and was found to be statistically no significant difference $(p>0.05)$.

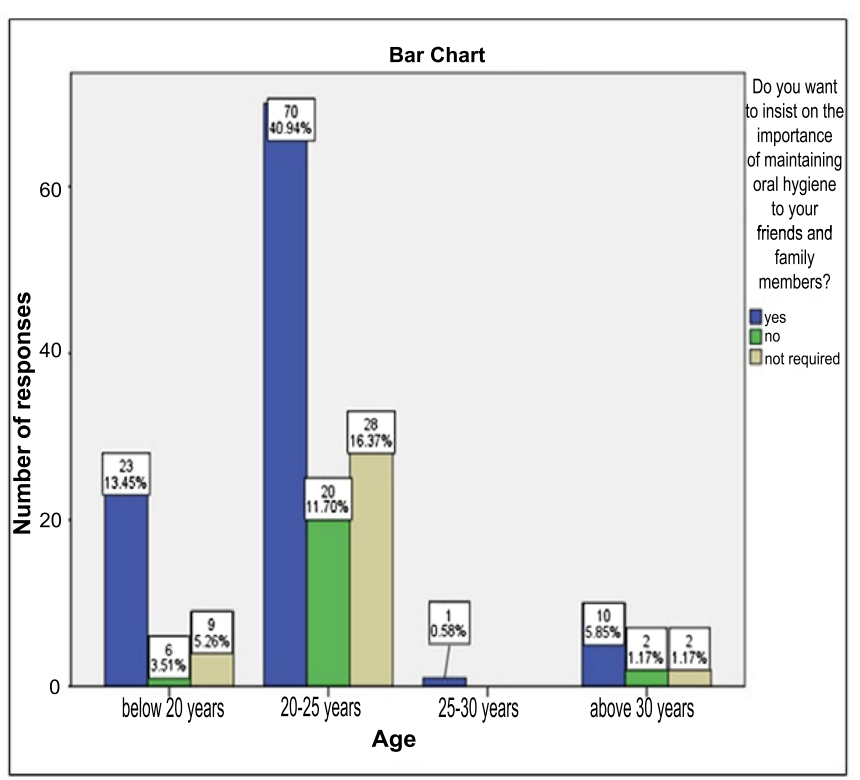

Figure 11: Bar chart showing the association between the different age groups of study population and the responses for the importance of maintaining oral hygiene. $X$-axis represents the different age groups and $Y$-axis represents the number of responses obtained. The majority of respondents belonging to the age group 20-25 years responded 'Yes' (40.94\%) The association was analyzed using chi-square test (1.519) and was found to be statistically no significant difference $(p>0.05)$.

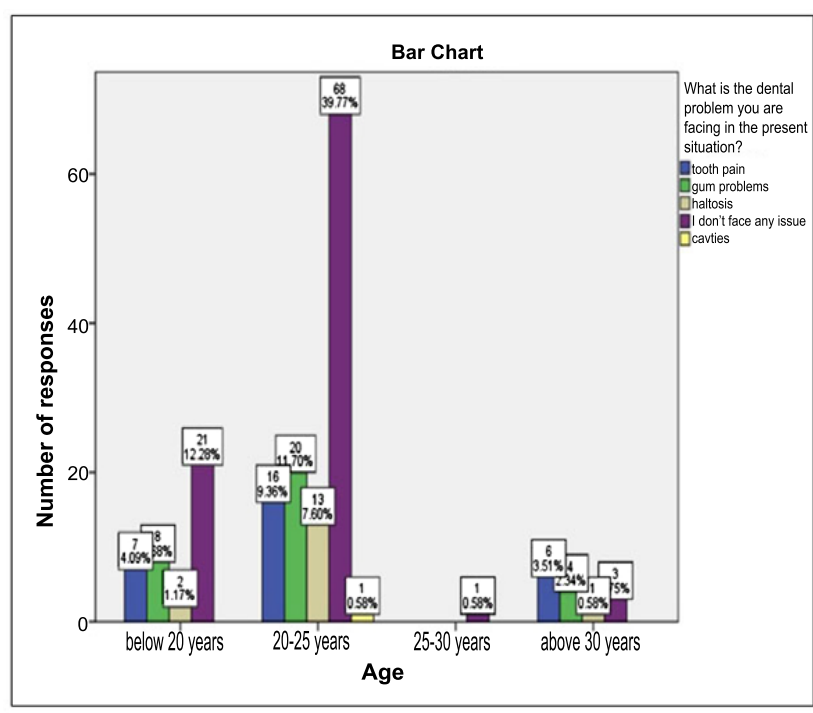

Figure 12: Bar chart showing the association between the different age groups and the dental problem faced in the present situation. $\mathrm{X}$-axis represents the different age groups of participants and $\mathrm{Y}$-axis represents the number of responses obtained. The majority of respondents belonging to the age group 20-25 years responded that they don't face any issues $(39.77 \%)$. The association was analyzed using chi square test (12.836) and was found to be statistically no significant difference $(p>0.05)$.

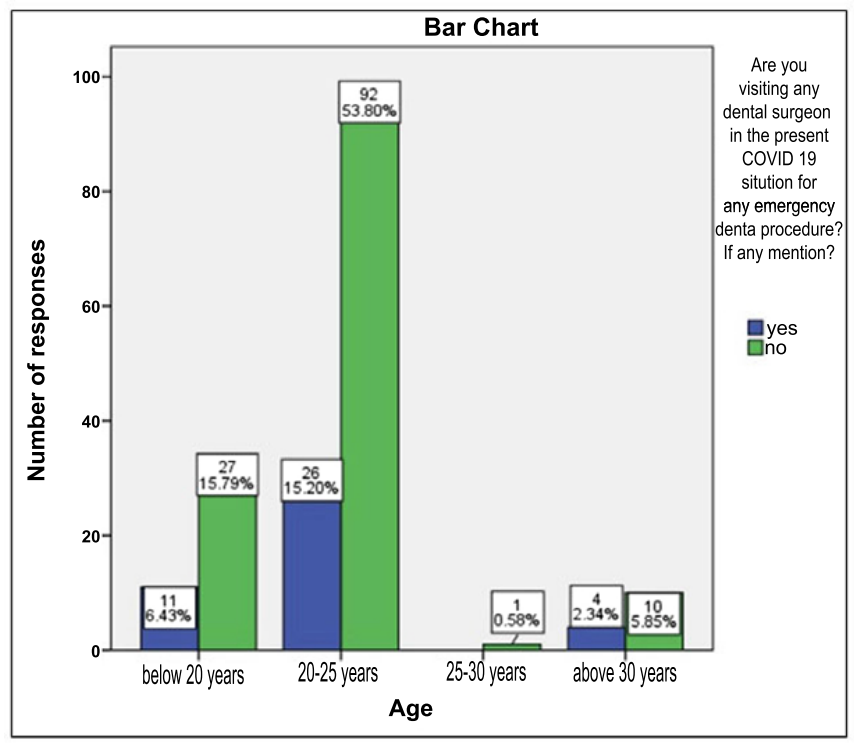

Figure 13: Bar chart showing the association between the different age groups of participants and responses for the people visiting dental surgeons in the present COVID-19 situation for any emergency dental procedures. $\mathrm{X}$-axis represents the different age groups of study population and Y-axis represents the number of responses obtained. The majority of respondents belonging to the age group 20-25 years responded ' $N o$ ' $(53.80 \%)$. The association was analyzed using chi-square test (1.237) and was found to be statistically no significant difference $(p>0.05)$. 


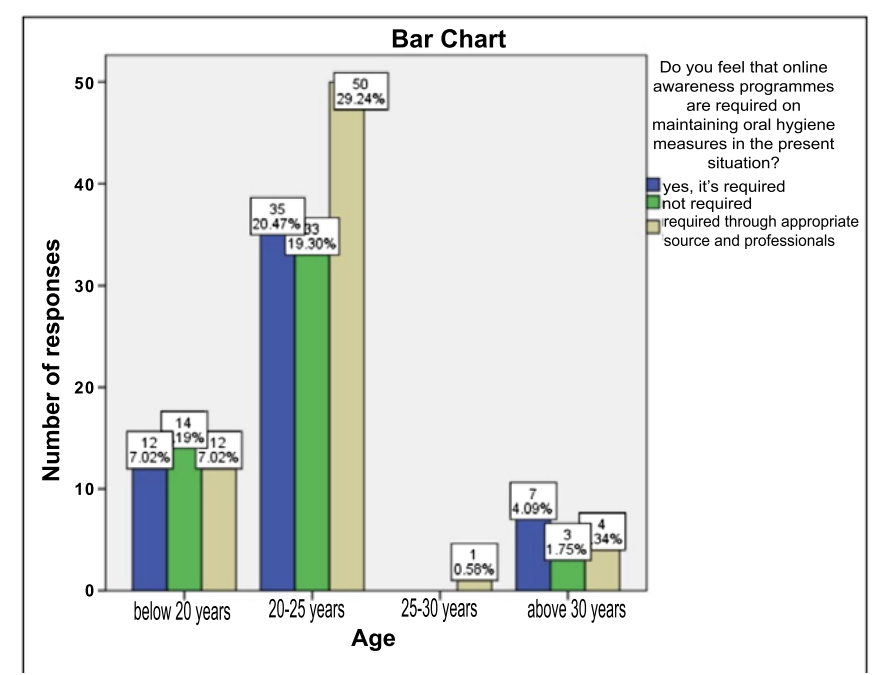

Figure 14: Bar chart showing the association between the participants of different age groups and the responses for requirement of awareness programmes maintaining oral hygiene measures in the present situation. $X$-axis represents the participants of different age groups and Y-axis represents the number of responses obtained. Majority of respondents belonging to the age group 20-25 years responded that they require an appropriate source to know about oral hygiene (29.24\%). The association was analyzed using chi-square test (5.572) and was found to be statistically no significant difference $(p>0.05)$.

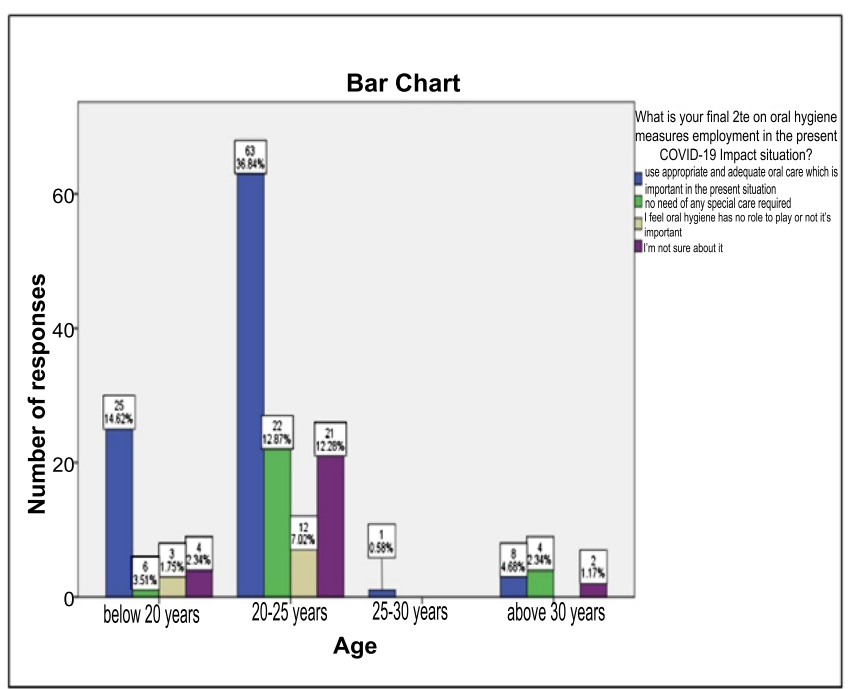

Figure 15: Bar chart showing the association between participants of different age groups and the final note on oral hygiene measures employment in the present COVID-19 impact situation. $X$ axis represents the different age groups of participants and the $Y$ axis represents the number of responses obtained. Majority of respondents belonging to the age group 20-25 years responded that they would require appropriate and adequate knowledge about oral care during this pandemic (36.84\%). The association was analyzed using chi square test (4.958) and was found to be statistically no significant difference $(p>0.05)$.
This study represented a broad overview about the awareness and attitude of dental treatments and maintenance of oral hygiene among the Chennai population. Among 174 participants participated in the study as mentioned in Tables 1-7. Nowadays, because of the changing lifestyle trends in the modern world, there have been changing ideas and perceptions about dental procedures and there is an evolving attitude towards the oral hygiene measures. Awareness about oral hygiene and its significance is very much essential in order to prevent the adverse effects of dental problems. So awareness of these oral hygiene practices might help in preserving oral cavity from dental problems. Surveys conducted among the age group of 20-25 years were having knowledge about oral hygiene. In the present study, certain age groups belonging to 20-25 years showed accuracy in responding $50.8 \%$ of this age group population felt that oral hygiene is as important as general measures. Pearson chi square test showed that $p$ value of $0.154(>0.05)$ which is statistically insignificant [Figure 1]. $81 \%$ of the study population felt dental checkup is more important when compared to other medical treatments ${ }^{61}$. No opposing finding has been found. To assess the oral health awareness and oral hygiene practices and provide insight into educational programs will be the better situation. In the present study, Age group 20-25 years $25.1 \%$ suggests that both brushing and usage of mouthwash will be the better hygiene measure. Pearson chi square test shows that $\mathrm{p}$ value of $0.634(>0.05)$ which is statistically insignificant [Figure 2]. $73.6 \%$ of the study population give importance to toothpaste when compared to other substanc$\mathrm{es}^{61}$. This is the similar study conducted by (Dileep et al) No opposing finding has been noticed. Limited knowledge and awareness of oral hygiene practices leads to poor oral health. In the present study Age group 20-25 years supported the regular visit of a dentist every 6 months $14.6 \%$ of this age group population follow the regular visit of dentist in the interval of every 6 months. Pearson chi square test shows that $p$ value of $0.120(>0.05)$ which is statistically insignificant [Figure 3]. $43.1 \%$ of the pre urban children had visited a dentist before. This shows that even children have the habit of taking care of their oral health. No opposing study was found ${ }^{62}$. In the present study Age group 20-25 years are aware of that poor dental health is linked to many serious dental problems. $40.3 \%$ of this age group accepts that poor oral health may lead to other periodontal problems. Pearson chi Square test showed a p-value of $0.694(>0.05)$ which is statistically insignificant [Figure 4]. 48.14\% of the children have reported that they had suffered from various dental problems in the past few years. Even children were aware of their dental health ${ }^{63}$. Lag of oral hygiene may lead to plaque formation and gingivitis. In the present study, Age group 20-25 years study population believe that maintaining oral health is very important even in COVID 19 situations. $35.6 \%$ of this age group population felt that oral health is very important as compared to medical general care. Pearson Chi-square test shows that $p$ value of 
$0.748(>0.05)$ which is statistically not significant [Figure 5]. No similar and opposing articles have been found. Oral diseases should have major public health concerns with high prevalence to create an impact on quality of life. In the present study a certain age group population of 20-25 years $13.4 \%$ do have consultation with dental surgeons about oral hygiene measures even in the current COVID 19 situation. Pearson Chi-square test shows that $\mathrm{P}$ value of $0.421(>0.05)$ which is statistically not significant [Figure 6]. No similar finding has been found. Motivating people towards better oral health practices and suggestions should be acquired from respected health professionals. The association between the different age groups of participants and the responses for frequency of brushing a day. Majority of respondents belonging to the age group 20-25 years had a habit of brushing once a day. Pearson chi square test shows that $p$ value of $0.809(>0.05)$ which is statistically not significant [Figure 7]. In the present study $28.65 \%$ of the population belonging to the age group 20-25 years has a habit of brushing twice a day. This shows a similar finding of my study ${ }^{64}$. In the present study Age group 20-25 years i.e., $47.95 \%$ of the respondents think it is very much essential to educate people about oral hygiene. Pearson chi square test shows that $\mathrm{P}$ value of $0.282(>0.05)$ which is statistically not significant [Figure 8]. In the present study $49.12 \%$ of the population belonging to the age group 20-25 years felt there is a scarcity of oral hygiene Equipments in the present COVID 19 situation. Pearson chi square test shows that $p$ value of $0.194(>0.05)$ which is statistically not significant [Figure 9]. In the present study $24.56 \%$ of the respondents felt Social media would be the better idea to obtain the source of information about oral hygiene. Pearson chi square test shows that $p$ value of $0.196(>0.05)$ which is statistically not significant [Figure 10]. No similar and opposing findings have been found yet. As the results show the relative answer for my finding. In the present study Age group 20-25 years of $40.9 \%$ insist on the importance of maintaining oral hygiene to friends and family members. Pearson chi square test shows that $\mathrm{P}$ value of $0.958(>0.05)$ which is statistically not significant [Figure 11]. 78\% of the population similar to this study supports oral hygiene ${ }^{65}$. Majority of the study population belong to the age group 20-25 years i.e., $39.77 \%$ of them felt they don't face any issues in the current Pandemic situation. Pearson Chi-square test shows a p-value of $0.381(>0.05)$ which is statistically not significant [Figure 12]. In the present study, $53.80 \%$ of the respondents belonging to the age group 20-25 years responded that they don't consult any dental practitioner in the current COVID situation. Pearson Chi-square test shows that the p-value of $0.744(>0.05)$ is statistically not significant [Figure 13]. $29.24 \%$ of the respondents belonging to the age group 20-25 years felt they would need an appropriate source to maintain oral hygiene. Pearson Chi-square test shows that a p-value of $0.473(>0.05)$ which is statistically not significant [Figure 14]. $36.84 \%$ of the respondents belonging to the age group
20-25 years responded that they would require appropriate and adequate knowledge about oral care during this pandemic. Pearson Chi-square test shows that the p-value of 0.838 $(>0.05)$ is statistically not significant [Figure 15].

\section{CONCLUSION}

In the present study, it was evident that most of the respondents were aware of oral hygiene practices in the present COVID-19 situation. The majority of the study population belonging to the age group 20-25 years was aware of oral hygiene practices. To obtain dental care during this pandemic seems to be very difficult as the situation is becoming worse every day. Hence, awareness and thorough knowledge about oral hygiene practices and care at home should be made aware to all to ensure better oral health.

\section{Limitations and Future Scope}

The study consists of small sample sizes. The questionnaire was general and it is not specific. It is not distributed widely. It is only distributed to a selected population. To improve the awareness of maintenance of oral hygiene, measures should be taken and the study should be expanded to more number of participants to create better knowledge of oral health and oral hygiene.

\section{ACKNOWLEDGEMENT}

With Sincere gratitude, we acknowledge the staff members of the department of Conservative Dentistry and Endodontics and Saveetha Dental College and study participants for their extended support towards the completion of research.

\section{Financial Support and Sponsorship}

Nil

\section{Conflicts of Interest}

Conflict of interest declared as none.

\section{REFERENCE}

1. Jain N, Mitra D, Ashok KP, et al. Oral hygiene, awareness and practice among patients attending OPD at Vyas Dental College and Hospital, Jodhpur. Journal of Indian Society of Periodontology 2012; 16: 524.

2. Jain N, Mitra D, Ashok KP, et al. Oral hygiene-awareness and practice among patients attending OPD at Vyas Dental College and Hospital, Jodhpur. J Indian Soc Periodontol 2012; 16: 524 528 .

3. Kapoor D, Kapoor P, Kaur I, et al. Oral hygiene awareness and practice amongst patients visiting the Department of Periodontology at a Dental College and Hospital in North India. Indian Journal of Dentistry 2014; 5: 64. 
4. Shah S, Professor A, Department of Dentistry, et al. Assessment of Smoking Habits, Oral Hygiene Practices and Self Perceived Malodour among the College Students in Ahmedabad. Indian Journal of Dental Education 2017; 10: 25-29.

5. Oberoi S, Mohanty V, Mahajan A, et al. Evaluating awareness regarding oral hygiene practices and exploring gender differences among patients attending for oral prophylaxis. Journal of Indian Society of Periodontology 2014; 18: 369.

6. Kulshrestha R. Assessment of Oral Hygiene awareness in Geriatric patients attending OPD at ESIC Dental College, Rohini, New Delhi. Journal of Oral Health and Craniofacial Science 2017; 2: 104-109.

7. Oswal KC. Oral Hygiene Practice Among Patients Visiting Terna Dental College. Journal of Oral Health and Community Dentistry 2013; 7: 33-36.

8. Behal R, Jan SM, Hussain H. Evaluation of Oral Hygiene Self Efficacy, Periodontal Knowledge, and Motivation among Young Patients Visiting Government Dental College and Hospital, Srinagar. International Journal of Contemporary Medical Research [IJCMR]; 5. Epub ahead of print 2018. DOI: 10.21276/ ijcmr.2018.5.10.16.

9. Singh A, Gambhir RS, Singh S, et al. Oral health: How much do you know? - A study on knowledge, attitude and practices of patients visiting a North Indian dental school. European Journal of Dentistry 2014; 08: 063-067.

10. Bunting RW. Oral Hygiene, https://books.google.com/books/ about/Oral_Hygiene.html?hl=\&id=XRzSAAAAMAAJ (1954).

11. Kleinman $\bar{D}$. Dental plaque control measures and oral hygiene practices: proceedings from a state-of-the-science workshop. Irl Pr, https://books.google.com/books/about/Dental_plaque_control_measures_and_oral.html?hl=\&id=MiFqAAAAMAAJ (1986).

12. Kiselnikova LP, Romanovskaya VN. [Ways of solving the problem of dentin hypersensitivity in children after professional oral hygiene]. Stomatologiia 2020; 99: 91-96.

13. Vpk V, Mohanty VR, Balappanavar AY, et al. Effectiveness of different parenting interventions on oral hygiene of cerebral palsy children: A randomized controlled trial. Spec Care Dentist. Epub ahead of print 2 June 2020. DOI: 10.1111/scd.12481.

14. Duman C. YouTube ${ }^{\mathrm{TM}}$ quality as a source for parent education about the oral hygiene of children. Int J Dent Hyg. Epub ahead of print 16 May 2020. DOI: 10.1111/idh.12445.

15. Inc. KN, Kernel Networks Inc. Oral Health Perception and Difficulties Encountered by Parents in the Implementation of Oral Hygiene of Children Under 6. Case Medical Research. Epub ahead of print 2019. DOI: $10.31525 /$ ct1-nct04123184.

16. Crawford P. An investigation into a measure of oral cleanliness and its usefulness in motivating children towards improved oral hygiene. http://isrctn.org/>. DOI: 10.1186/isrctn10044161.

17. Yiğit T. Are the oral hygiene habits of parents parallel to the children? DOI: 10.26226/morressier.5ac3832d2afeeb00097a40f2.

18. The oral health status of the preschool child according to the oral health management behaviors performed by their parents. Journal of Korean Society of Dental Hygiene; 17. Epub ahead of print 2017. DOI: 10.13065/jksdh.2017.17.06.1225.

19. Djordjevic A. Parents' Knowledge about the Effects of Oral Hygiene, Proper Nutrition and Fluoride Prophylaxis on Oral Health in Early Childhood. Balkan Journal of Dental Medicine 2018; 22: $26-31$.

20. Seo S-Y, Lee S-H, Kim D-Y. Influence of parents' knowledge for oral hygiene on the oral health of their infants. Journal of Korean society of Dental Hygiene 2012; 12: 1101-1110.

21. Amin TT, Al-Abad BM. Oral hygiene practices, dental knowledge, dietary habits and their relation to caries among male pri- mary school children in Al Hassa, Saudi Arabia. International Journal of Dental Hygiene 2008; 6: 361-370.

22. Halawany HS, Al Badr A, Al Sadhan S, et al. Effectiveness of oral health education intervention among female primary school children in Riyadh, Saudi Arabia. The Saudi Dental Journal 2018; 30: 190-196.

23. AlGhamdi AS, Almarghlani AA, Alyafi RA, et al. Gingival health and oral hygiene practices among high school children in Saudi Arabia. Annals of Saudi Medicine 2020; 40: 126-135.

24. Hazzani SAA, Al Hazzani SA, Alanazi EZ, et al. Prevalence of Dental Caries and Its Relationship with Oral Hygiene and Type of Female Schools in Al-Kharj City, Kingdom of Saudi Arabia. Journal of Oral Health and Community Dentistry 2019; 13: $17-20$.

25. Uloopi KS, Chowdary P, Vinay C, et al. Impact of verbal, braille text, and tactile oral hygiene awareness instructions on oral health status of visually impaired children. Journal of Indian Society of Pedodontics and Preventive Dentistry 2016; 34: 43.

26. Vinay C, Uloopi KS, Sekhar R, et al. Impact of visual instruction on oral hygiene status of children with hearing impairment. Journal of Indian Society of Pedodontics and Preventive Dentistry $2014 ; 32: 39$.

27. Wei SHY. Pediatric Dentistry: Total Patient Care, https://books.google.com/books/about/Pediatric_Dentistry. html?hl=\&id=eixqAAAAMAAJ (1988).

28. Choo A, Delac DM, Messer LB. Oral hygiene measures and promotion: review and considerations. Aust Dent J 2001; 46: 166-173.

29. Desai M, Messer LB, Calache H. A study of the dental treatment needs of children with disabilities in Melbourne, Australia. Australian Dental Journal 2001; 46: 41-50.

30. Chalmers JM. Oral health promotion for our ageing Australian population. Australian Dental Journal 2003; 48: 2-9.

31. Oberoi S, Sharma G, Oberoi A. A cross-sectional survey to assess the effect of socioeconomic status on the oral hygiene habits. Journal of Indian Society of Periodontology 2016; 20: 531.

32. Ahad M, Gheena S. Awareness, attitude and knowledge about evidence based dentistry among the dental practitioner in Chennai city. Research Journal of Pharmacy and Technology 2016; 9: 1863 .

33. Kamath A, Patil V, Walimbe H, et al. Oral hygiene awareness among school children of rural Mangalore. Journal of Dental Research and Review 2014; $1: 7$.

34. Mathur MR, Tsakos G, Parmar P, et al. Socioeconomic inequalities and determinants of oral hygiene status among Urban Indian adolescents. Community Dentistry and Oral Epidemiology. Epub ahead of print 2016. DOI: 10.1111/cdoe.12212.

35. Kaur M, Grewal N. Status of oral health awareness in Indian children as compared to Western children: A thought provoking situation (A pilot study). Journal of Indian Society of Pedodontics and Preventive Dentistry 2007; 25: 15.

36. Richa, Richa, Yashoda R, et al. Oral health status and parental perception of child oral health related quality-of-life of children with autism in Bangalore, India. Journal of Indian Society of Pedodontics and Preventive Dentistry 2014; 32: 135.

37. Ashwath B, Vijayalakshmi R, Malini S. Self-perceived halitosis and oral hygiene habits among undergraduate dental students. J Indian Soc Periodontol 2014; 18: 357-360.

38. Setia S, Pannu P, Gambhir R, et al. Correlation of oral hygiene practices, smoking and oral health conditions with self perceived halitosis amongst undergraduate dental students. Journal of Natural Science, Biology and Medicine 2014; 5: 67.

39. Basnet BB, Sharma KR. Oral Hygiene and Tobacco Use Practices in Rural Villages of Jhapa District, Nepal. J Nepal Health Res Counc 2020; 18: 59-63. 
40. Shahi AK, Chandra S, Kumar S, et al. Oral Health Behavior and Factors Influencing the Selection of Oral Hygiene Products among the Adolescent Tobacco Consumers in Jharkhand. J Contemp Dent Pract 2019; 20: 1200-1205.

41. Gupta B, Bray F, Kumar N, et al. Associations between oral hygiene habits, diet, tobacco and alcohol and risk of oral cancer: A case-control study from India. Cancer Epidemiology 2017; 51: 7-14.

42. C J, Janakiram C, Joseph J. Prevalence and Dependency of Tobacco Use in an Indigenous Population of Kerala, India. Journal of Oral Hygiene \& Health; 04. Epub ahead of print 2016. DOI: 10.4172/2332-0702.1000198.

43. Erratum: Social predictors of oral hygiene status in school children from suburban Nigeria. Brazilian Oral Research; 33. Epub ahead of print 2019. DOI: 10.1590/1807-3107bor-2019. vol33.0022erratum.

44. Jacobsson B. Oral Health of Children and Adolescents in Da Nang. Journal of Oral Hygiene \& Health; 02. Epub ahead of print 2014. DOI: 10.4172/2332-0702.1000145.

45. Walker A. Oral Hygiene for Children. Journal of School Health 1931; 1: 8-10.

46. Ramamoorthi S, Nivedhitha MS, Divyanand MJ. Comparative evaluation of postoperative pain after using endodontic needle and EndoActivator during root canal irrigation: A randomised controlled trial. Aust Endod J 2015; 41: 78-87.

47. Hussainy SN, Nasim I, Thomas T, et al. Clinical performance of resin-modified glass ionomer cement, flowable composite, and polyacid-modified resin composite in noncarious cervical lesions: One-year follow-up. J Conserv Dent 2018; 21: 510-515.

48. Noor SSSE, S Syed Shihaab, Pradeep. Chlorhexidine: Its properties and effects. Research Journal of Pharmacy and Technology 2016; 9: 1755.

49. Janani K, Palanivelu A, Sandhya R. Diagnostic accuracy of dental pulse oximeter with customized sensor holder, thermal test and electric pulp test for the evaluation of pulp vitality - An in vivo study. Brazilian Dental Science; 23. Epub ahead of print 2020. DOI: 10.14295/bds.2020.v23i1.1805.

50. Nasim I, Nandakumar M. Comparative evaluation of grape seed and cranberry extracts in preventing enamel erosion: An optical emission spectrometric analysis. Journal of Conservative Dentistry 2018; 21: 516.

51. Ramanathan S, Solete P. Cone-beam Computed Tomography Evaluation of Root Canal Preparation using Various Rotary Instruments: An in vitro Study. The Journal of Contemporary Dental Practice 2015; 16: 869-872.

52. Siddique R, Sureshbabu NM, Somasundaram J, et al. Qualitative and quantitative analysis of precipitate formation following interaction of chlorhexidine with sodium hypochlorite, neem, and tulsi. J Conserv Dent 2019; 22: 40-47.

53. R R, Rajakeerthi R, Ms N. Natural Product as the Storage medium for an avulsed tooth - A Systematic Review. Cumhuriyet Dental Journal 2019; 22: 249-256.
54. Rajendran R, Kunjusankaran RN, Sandhya R, et al. Comparative Evaluation of Remineralizing Potential of a Paste Containing Bioactive Glass and a Topical Cream Containing Casein Phosphopeptide-Amorphous Calcium Phosphate: An in Vitro Study. Pesquisa Brasileira em Odontopediatria e Clínica Integrada 2019; 19: 1-10.

55. Kumar D, Delphine Priscilla Antony S. Calcified Canal and Negotiation-A Review. Research Journal of Pharmacy and Technology 2018; 11: 3727.

56. Ravinthar K, Jayalakshmi. Recent Advancements in Laminates and Veneers in Dentistry. Research Journal of Pharmacy and Technology 2018; 11: 785.

57. Ramesh S, Teja K, Priya V. Regulation of matrix metalloproteinase-3 gene expression in inflammation: A molecular study. Journal of Conservative Dentistry 2018; 21: 592.

58. Jose J, P. A, Subbaiyan H. Different Treatment Modalities followed by Dental Practitioners for Ellis Class 2 Fracture - A Questionnaire-based Survey. The Open Dentistry Journal 2020; 14: 59-65.

59. Teja KV, Ramesh S. Is a filled lateral canal - A sign of superiority? Journal of Dental Sciences. Epub ahead of print 2020. DOI: 10.1016/j.jds.2020.02.009.

60. Manohar M, Sharma S. A survey of the knowledge, attitude, and awareness about the principal choice of intracanal medicaments among the general dental practitioners and nonendodontic specialists. Indian Journal of Dental Research 2018; 29: 716.

61. Khurana S, Dileep CL, Jayaprakash K, et al. Oral health status of battery factory workers in Kanpur city: A cross-sectional study. Journal of Indian Association of Public Health Dentistry 2014; 12: 80 .

62. Maina LC, Karanja S, Kombich J. Immunization coverage and its determinants among children aged 12 - 23 months in a periurban area of Kenya. Pan African Medical Journal; 14. Epub ahead of print 2013. DOI: 10.11604/pamj.2013.14.3.2181.

63. Oral Hygiene Status, Knowledge, Attitude and Practices of Oral Health among Rural Children of Kanchipuram District - ProQuest, http://search.proquest.com/openview/4cc45e5b3c4acb faeb5a99bec2008def/1?pq-origsite $=$ gscholar\&cbl=1316336\& casa_token $=$ XCyKS1XqPP0AAAAA:xIk6hTzW1W2t2_SIIUbXs6r9SiHiMDdoFiXiReJ_zXWFBbkIt40uZwwFFhPcoRnAu1Qx-FApxUA (accessed 7 June 2020).

64. Shah AG. Evaluation of Oral Hygiene Awareness, Oral Health Practices and Dental Health Problems among the Undergraduate Medical Students of India. International Journal of Preventive and Clinical Dental Research 2017; 4: 109-113.

65. Almas K, Al-Hawish A, Al-Khamis W. Oral Hygiene Practices, Smoking Habits, and Self-Perceived Oral Malodor Among Dental Students. The Journal of Contemporary Dental Practice 2003; 4: 77-90. 